\title{
Cáncer de mama familiar, BRCA1 positivo*
}

\author{
Drs. LUIS FIGUEROA G. ${ }^{1}$, ENRIQUE BARGALLO R. ${ }^{2}$, \\ GERARDO CASTORENA R. ${ }^{3}$, SOFÍA VALANCI A. ${ }^{1}$ \\ Residente de Cirugía General, Centro Médico ABC. \\ 2 Cirujano Oncólogo, Jefe del Departamento de Mama, Instituto Nacional de Cancerología. \\ 3 Cirujano Oncólogo, Centro Médico ABC. \\ México DF, México
}

Abstract

\section{Familiar breast cancer, positive BRCA1}

51 year old female found on check up a suspicious lesion in right breast, BIRADS IVa. Pathology reported a ductal infiltrative moderately differentiated cancer with two separate carcinomas of 2 and $1 \mathrm{~mm}$ each, progesterone and estrogen receptors. Familiar breast cancer is calculated to be about $5-10 \%$ of all breast cancers. The genes involved are: BCRA1 in 20\%, BRCA2 in $20 \%$, CHEK 2 in $5 \%$, TP 53 in 1\%, although more than $50 \%$ of cases are not associated with a gen. BRCA1 is a gene in chromosome $17 \mathrm{q} 21$, tumor suppressor, involved in the regulation of the cellular cycle, repair of damaged DNA, maintenance of genomic stability and regulation of transcription. Specific indications are in use for BCRA gene scouting in women with family or personal history of breast or ovary cancer.

Key words: Familiar breast cancer, BCRA1 gene.

\section{Resumen}

Paciente de género femenino de 51 años que en una revisión de rutina se observó lesión sospechosa de mama derecha, BIRADS IVa. Patología reportó cáncer ductal infiltrante moderadamente diferenciado con dos focos de carcinoma invasor separados de 2 y $1 \mathrm{~mm}$, receptores de estrógeno y progesterona positivos. El cáncer de mama familiar abarca entre el 5\% al 10\% de cáncer de mama de la población en general. Los genes involucrados en este padecimiento son: BRCA1 en 20\%, BRCA 2 en 20\%, CHEK2 en 5\%, TP 53 en $1 \%$, sin embargo, en más del $50 \%$ de los casos se desconoce en gen asociado. El BRCA1 es un gen localizado en el cromosoma 17q21, supresor de tumor, involucrado en la regulación del ciclo celular, reparación del ADN dañado, mantenimiento de la estabilidad genómica y regulación de la transcripción. Existen indicaciones precisas para la búsqueda intencionada del gen BRCA en pacientes con historia familiar o personal de cáncer de mama y ovario.

Palabras clave: Cáncer de mama familiar, BRCA1.

\footnotetext{
*Recibido el 31 de Marzo de 2009 y aceptado para publicación el 31 de Julio de 2009.

Correspondencia: Dr. Luis Figueroa G.

Sur 126 \#116 Col. Las Américas. Alvaro Obregón, Distrito Federal 03510, México.

E-mail: drluisfigueroa@sbcglobal.net
} 


\section{Introducción}

El cáncer de mama familiar abarca del 5\% al 10\% de cáncer de mama de la población en general. Los genes involucrados en este padecimiento son: BRCA 1 en 20\%, BRCA 2 en 20\%, CHEK 2 en 5\%, TP 53 en $1 \%$, sin embargo, más del $50 \%$ de los casos se desconoce en gen asociado ${ }^{1}$.

\section{Caso clínico}

Mujer de 51 años que en una revisión de rutina observó una lesión sospechosa de mama derecha, BIRADS IVa. Se realizó biopsia excisional con resultado de cáncer ductal infiltrante moderadamente diferenciado con dos focos de carcinoma invasor separados uno de $2 \mathrm{~mm}$ y otro de $1 \mathrm{~mm}$. Sin invasión vascular ni perineural. Receptores de estrógeno y progesterona positivo. Receptores Her2/neu negativos. BRCA 1 positivo con mutación en la base 4,182 , que codifica para el aminoácido 1,364 para un codón de paro prematuro.

Cuenta con los siguientes antecedentes de importancia: Abuelo materno con cáncer de colon, tía materna con cáncer de mama, menarquia a los 14 años, ritmo $28 \times 7$. Inicio de vida sexual activa a los 24 años; con 2 abortos.

Se realizó mastectomía bilateral conservadora de piel, con ganglio centinela derecho (negativo para metástasis) y primer tiempo de reconstrucción con expansores.

\section{Discusión}

El BRCA1 es un gen localizado en el cromosoma 17q21, con herencia autosómica dominante y de alta penetrancia. Está conformado por 5,592 bases, un peso de $207 \mathrm{KDa}$ y estructuralmente formado por 22 exones y 1,863 aminoácidos. Es un gen supresor de tumor, involucrado en la regulación del ciclo celular, reparación del ADN dañado, mantenimiento de la estabilidad genómica y regulación de la transcripción. $^{2}$ Las mutaciones detectadas en este gen son: deleciones, inserciones, mutaciones puntuales, mutaciones sin sentido (codones de detención prematura), hipermetilación de la región promotora. ${ }^{3}$

La mutación del BRCA 1 se da principalmente en grupos étnicos como los judíos Ashkenazi, grupos familiares de Noruega, Islandia, Suecia y Polonia. Dentro de las características sobresalientes en el cáncer de mama asociado a BRCA1 son: edad más temprana, mayor propensión a la multifocalidad y bilateralidad, alto índice mitótico y receptores estrógenos y progestágenos negativos ${ }^{4,5}$.
Para evaluar el riesgo de portar mutaciones patológicas del BRCA1, se pueden utilizar algunas escalas como la de Tyrer-Cuzick, BRCAPRO, Manchester o Frank ${ }^{6}$ (Tablas 1 y 2).

Las indicaciones absolutas aceptadas para realizar un estudio genético son ${ }^{7}$ :

\section{Historia familiar de cáncer de mama en:}

- Dos familiares, uno de primer grado y diagnosticada antes de los 50 años.

- Tres o más familiares de primero o segundo grado, sin importar la edad del diagnóstico.

- Uno o más familiares con cáncer de mama asociado a cáncer de ovario, sin importar si son de primer o segundo grado.

- Familiar de primer grado con cáncer de mama bilateral.

- Familiar de primer grado, hombre, con cáncer de mama.

- Historia familiar de cáncer de ovario en dos o más familiares de primero o segundo grado.

Estas indicaciones son recomendaciones tipo B en pacientes que tengan uno o más de los criterios mencionados. Mientras que para pacientes que no presentan ningún criterio es una recomendación tipo D.

La mastografía ha demostrado una reducción de la mortalidad del $16 \%$, dentro de la población en general. Sin embargo, en pacientes con mutación del gen BRCA 1, existen algunos puntos importantes a tomar en cuenta por lo que la reducción en la mortalidad podría no ser tan significativa. Como principales puntos tenemos que la presentación del cáncer de mama en estas pacientes se detecta a edad más temprana y por lo tanto, la densidad mamaria es mayor, además de que los tumores asociados a este gen presentan un crecimiento más rápido ${ }^{4}$. Actualmente, la resonancia magnética ha tomado un papel de gran importancia para la detección en mujeres con predisposición genética como lo señala el estudio UK-MARIBS en el 2005, quien encontró una sensibilidad del $75 \%$ y un valor predictivo positivo superior al $45 \%$, en lesiones BI-RADS IV- $\mathrm{V}^{4}$.

Los tratamientos para la disminución del riesgo de cáncer de mama para pacientes con predisposición se dividen en químico y quirúrgico. Dentro del grupo de prevención química el más estudiado es el tamoxifen, que usado por 5 años demostró una disminución del $43 \%$ en la recurrencia de cáncer de mama, sin embargo, aumenta el riesgo de trombosis venosa profunda y cáncer de endometrio. Se está estudiando el uso de ramoxifen, que en estudios preliminares, demostró una disminución similar al tamoxifen, pero con disminución en el riesgo de trombosis venosa profunda y cáncer de endometrio. 
Tabla 1. Prevalencia de deleciones en el BRCA1 y BRCA2 (excluye herencia Ashkenazi)

\begin{tabular}{|c|c|c|c|c|c|c|}
\hline \multirow[b]{2}{*}{$\begin{array}{l}\text { Historia } \\
\text { Personal }\end{array}$} & \multirow[b]{2}{*}{$\begin{array}{l}\text { No cáncer de } \\
\text { mama }<50, \\
\text { o cáncer de } \\
\text { ovario en } \\
\text { ningún } \\
\text { familiar }\end{array}$} & \multirow[b]{2}{*}{$\begin{array}{c}\text { Cáncer de mama } \\
<50 \text { en un } \\
\text { familiar, no } \\
\text { cáncer de } \\
\text { ovario }\end{array}$} & \multicolumn{2}{|c|}{ Historia Familiar } & \multirow[b]{2}{*}{$\begin{array}{l}\text { Cáncer de } \\
\text { ovario en } \\
\text { más de un } \\
\text { familiar, sin } \\
\text { cáncer de } \\
\text { mama }\end{array}$} & \multirow[b]{2}{*}{$\begin{array}{c}\text { Cáncer de } \\
\text { mama }<\mathbf{5 0} \\
\text { y cáncer de } \\
\text { ovario a } \\
\text { cualquier edad }\end{array}$} \\
\hline & & & $\begin{array}{c}\text { Cáncer de } \\
\text { mama }<50 \\
\text { en uno o más } \\
\text { familiares, } \\
\text { no cáncer } \\
\text { de ovario }\end{array}$ & $\begin{array}{l}\text { Cáncer de } \\
\text { ovario en } \\
\text { cualquier } \\
\text { edad en un } \\
\text { familiar, no } \\
\text { cáncer de mama }\end{array}$ & & \\
\hline $\begin{array}{l}\text { Sin cáncer } \\
\text { de mama u } \\
\text { ovario }\end{array}$ & $2,80 \%$ & $4,50 \%$ & $8,70 \%$ & $5,60 \%$ & $9,60 \%$ & $12,20 \%$ \\
\hline $\begin{array}{l}\text { Cáncer de } \\
\text { mama }>50\end{array}$ & $2,90 \%$ & $5,30 \%$ & $11,40 \%$ & $6,40 \%$ & $12,20 \%$ & $15,90 \%$ \\
\hline $\begin{array}{l}\text { Cáncer de } \\
\text { mama }<50\end{array}$ & $6,50 \%$ & $15,80 \%$ & $30,10 \%$ & $16,90 \%$ & $27,30 \%$ & $39,20 \%$ \\
\hline $\begin{array}{l}\text { Cáncer de } \\
\text { mama } \\
\text { masculino }\end{array}$ & $12,80 \%$ & $21,80 \%$ & $41,90 \%$ & $20 \%$ & $40 \%$ & $61,90 \%$ \\
\hline $\begin{array}{l}\text { Cáncer de } \\
\text { ovario a } \\
\text { cualquier } \\
\text { edad, no } \\
\text { cáncer de } \\
\text { mama }\end{array}$ & $8,80 \%$ & $23,10 \%$ & $42,30 \%$ & $21,10 \%$ & $33,20 \%$ & $48,50 \%$ \\
\hline $\begin{array}{l}\text { Cáncer de } \\
\text { mama }>50 \\
\text { y cáncer de } \\
\text { ovario a } \\
\text { cualquier edad }\end{array}$ & $17,60 \%$ & $26,10 \%$ & $46,20 \%$ & $30,30 \%$ & $46,20 \%$ & $60 \%$ \\
\hline $\begin{array}{l}\text { Cáncer de } \\
\text { mama }<50 \\
\text { y cáncer de } \\
\text { ovario a } \\
\text { cualquier edad }\end{array}$ & $39,10 \%$ & $53,90 \%$ & $67,20 \%$ & $66 \%$ & $70,80 \%$ & $79 \%$ \\
\hline
\end{tabular}

Prevalencia de mutación en BRCA 1 y BRCA 2 (se excluyen individuos Ashkenazi). Tomado de: Frank TS. Clinical Characterisitics of Individuals with Germline Mutations in BRCA1 and BRCA2: Analysis of 10000 individuals. Journal of Clinical Oncology. 20: 1480-1490, 2002.

De forma experimental se investiga el uso de GnRH, hGC para promover la diferenciación de la mama y disminuir su densidad.

Así mismo, la ooforectomía bilateral ha demostrado una reducción hasta del $50 \%$ en recurrencia del cáncer de mama. Sin embargo, no se cuenta con ningún estudio de evidencia sólida al respecto ${ }^{8}$. En pacientes menores de 40 años portadores de BRCA, se observó una disminución de la incidencia en un $50 \%{ }^{9}$.

El papel de la mastectomía bilateral profiláctica en pacientes de alto riesgo como los portadores de
BRCA, han demostrado una reducción del $85 \%$ al $100 \%$ en cáncer de mama. Meijers, en un estudio con 76 pacientes demostró una disminución del riesgo del $100 \%$ a 2,9 años y Hartmann con 26 pacientes una disminución del riesgo en $100 \%$ a 13,4 años. El estudio PROSE, que estudió a 105 pacientes, observó una disminución del riesgo del $90 \%$ a 6,4 años 9 .

Grann desarrolló un sistema matemático, en una supuesta paciente de 40 años con mutación del gen BRCA y llegó a la conclusión de que existe un aumento en la sobrevida de acuerdo a la terapia profiláctica utilizada. Con tamoxifen la sobrevida au- 
Tabla 2. Prevalencia de deleciones en el BRCA1 y BRCA2 en individuos Ashkenazi

\begin{tabular}{|c|c|c|c|c|c|c|}
\hline \multirow[b]{2}{*}{$\begin{array}{l}\text { Historia } \\
\text { Personal }\end{array}$} & \multirow[b]{2}{*}{$\begin{array}{l}\text { No cáncer de } \\
\text { mama }<50 \text {, } \\
\text { o cáncer de } \\
\text { ovario en } \\
\text { ningún } \\
\text { familiar }\end{array}$} & \multirow[b]{2}{*}{$\begin{array}{c}\text { Cáncer de mama } \\
<50 \text { en un } \\
\text { familiar, no } \\
\text { cáncer de } \\
\text { ovario }\end{array}$} & \multicolumn{2}{|c|}{ Historia Familiar } & \multirow[b]{2}{*}{$\begin{array}{l}\text { Cáncer de } \\
\text { ovario en } \\
\text { más de un } \\
\text { familiar, sin } \\
\text { cáncer de } \\
\text { mama }\end{array}$} & \multirow[b]{2}{*}{$\begin{array}{c}\text { Cáncer de } \\
\text { mama }<50 \\
\text { y cáncer de } \\
\text { ovario a } \\
\text { cualquier edad }\end{array}$} \\
\hline & & & $\begin{array}{c}\text { Cáncer de } \\
\text { mama }<50 \\
\text { en uno o más } \\
\text { familiares, } \\
\text { no cáncer } \\
\text { de ovario }\end{array}$ & $\begin{array}{l}\text { Cáncer de } \\
\text { ovario en } \\
\text { cualquier } \\
\text { edad en un } \\
\text { familiar, no } \\
\text { cáncer de mama }\end{array}$ & & \\
\hline $\begin{array}{l}\text { Sin cáncer } \\
\text { de mama u } \\
\text { ovario }\end{array}$ & $6,9 \%$ & $13,7 \%$ & $19,90 \%$ & $15,50 \%$ & $23,60 \%$ & $27,50 \%$ \\
\hline $\begin{array}{l}\text { Cáncer de } \\
\text { mama }>50\end{array}$ & $4,40 \%$ & $9,40 \%$ & $11,30 \%$ & $15,80 \%$ & $20,00 \%$ & $19,90 \%$ \\
\hline $\begin{array}{l}\text { Cáncer de } \\
\text { mama }<50\end{array}$ & $12,00 \%$ & $24,20 \%$ & $36,30 \%$ & $38,80 \%$ & $59,20 \%$ & $51,40 \%$ \\
\hline $\begin{array}{l}\text { Cáncer de } \\
\text { mama } \\
\text { masculino }\end{array}$ & $15,00 \%$ & $30,80 \%$ & $0,00 \%$ & $40,00 \%$ & $100,00 \%$ & $70,00 \%$ \\
\hline $\begin{array}{l}\text { Cáncer de } \\
\text { ovario a } \\
\text { cualquier } \\
\text { edad, no } \\
\text { cáncer de } \\
\text { mama }\end{array}$ & $22,20 \%$ & $37,00 \%$ & $60,60 \%$ & $42,00 \%$ & $43,20 \%$ & $72,30 \%$ \\
\hline $\begin{array}{l}\text { Cáncer de } \\
\text { mama }>50 \\
\text { y cáncer de } \\
\text { ovario a } \\
\text { cualquier edad }\end{array}$ & $29,50 \%$ & $54,30 \%$ & $50,00 \%$ & $50,00 \%$ & $100,00 \%$ & $63,60 \%$ \\
\hline $\begin{array}{l}\text { Cáncer de } \\
\text { mama }<50 \\
\text { y cáncer de } \\
\text { ovario a } \\
\text { cualquier edad }\end{array}$ & $71,10 \%$ & $88,90 \%$ & $80,00 \%$ & $90,90 \%$ & $100,00 \%$ & $75,00 \%$ \\
\hline
\end{tabular}

Prevalencia de mutación en BRCA 1 y BRCA 2 en individuos Ashkenazi. Tomado de: Frank TS. Clinical Characterisitics of Individuals with Germline Mutations in BRCA1 and BRCA2: Analysis of 10000 individuals. Journal of Clinical Oncology. 20: 1480-1490, 2002.

menta 1,8 años, con ooforectomía profiláctica 2,6 años, tamoxifen y ooforectomía 4,6 años, mastectomía profiláctica 3,5 años y con mastectomía y ooforectomía 4,9 años ${ }^{10}$.

La prevalencia de esta mutación en la población de América Latina es baja, posiblemente menor que en países con población totalmente caucásica. La detección oportuna de las pacientes con alta probabilidad de ser portadoras de esta mutación mejora drásticamente la sobrevida y nos permite un seguimiento más estrecho a la paciente y a su descendencia.

\section{Referencias}

1. Wooster R, Weber B. Genomic Medicine. Breast and ovarian cancer. NEJM 2003; 348: 2339-2347.

2. Yarden R, Papa M., BRCA1 at the crossroad of multiple cellular pathways: approaches for therapeutic interventions. Review Mol Cancer Ther 2006; 5: 13961404.

3. Langston A, Malone K, Thompson J, Daling J, Ostrander E. BRCA 1 mutation in a population-based sample of young women with breast cancer. NEJM 1996; 334: 137-142. 
4. Sarin R. A decade of discovery of BRCA1 and BRCA2: Are we turning the tide against hereditary breast cancers? Editorial. J Cancer Res Ther 2006; 2: 157 158 .

5. Hedenfalk I, Duggan D, Chen Y, Radmacher M, Bittner M, Simon R, et al. Gene-expression profiles in hereditary breast cancer. NEJM 2002; 344: 539548.

6. Frank TS, Deffenbaugh AM, Reid JE, Hulick M, Ward $\mathrm{BE}$, Lingerfelter B, et al. Clinical Characteristics of Individuals With Germline Mutations in BRCA1 and BRCA2: Analysis of 10,000 Individuals. Journal of Clinical Oncology 2002; 20: 1480-1490.

7. U.S. Preventive Services Task Force. Genetic Risk
Assessment and BRCA Mutation Testing for Breast and Ovarian Cancer Susceptibility: Recommendation Statement. Am Fam Phys 2006; 73: 869-874.

8. Robson M, Offit K. Management of an Inherited Predisposition to Breast Cancer. NEJM 2007; 357: 154-162.

9. Zakaria S, Degnim AC. Prophylactic mastectomy. Surg Clin N Am. 2007; 87: 317-331.

10. Grann V, Jacobson J, Thomason D, Hershman D, Heitjan D, Neugut A, et al. Effect of Prevention Strategies on Survival and Quality- Adjusted Survival of Women With BRCA1/2 Mutations: An Updated Decision Analysis. Journal of Clinical Oncology 2002; 20: 2520-2529. 